\title{
Planetary health: from concept to decisive action
}

Planetary health sets the ambitious task of understanding the dynamic and systemic relationships between global environmental changes, their effects on natural systems, and how changes to natural systems affect human health and wellbeing at multiple scales: global (eg, climate), regional (eg, transboundary fire emissions), and local (eg, persistent organic pollutants). By emphasising interconnections between human health and environmental changes and enabling holistic thinking about overlapping challenges and integrated solutions for present and future generations, the concept of planetary health offers an opportunity to advance the 2030 Agenda for Sustainable Development, including identification of co-benefits across targets, encouraging effective cross-sector action and partnerships, and ensuring policy coherence. ${ }^{1}$ In turn, the agenda of the Sustainable Development Goals (SDGs) offers substantial opportunities to advance planetary health. As the scientific evidence strengthens and public appreciation of humanity's dependence on the state of natural systems increases, now is the time to move from concept to decisive action to protect planetary health.

Moving beyond a conceptual approach to advance actions for planetary health, and for the SDGs, requires monitoring of and reporting on indicators relevant to planetary health that capture the scope, spatial, and time scales of changes to natural systems affecting human health and wellbeing and to assess the effects of potential solutions. A fortified evidence base on planetary health solutions, including their costs, trade-offs, and effects on the most vulnerable and marginalised groups, could accelerate the development, prioritisation, coordination, and implementation of key policy actions to protect planetary health at local, national, regional, and global levels. Monitoring of planetary health can build on existing indicators including for the SDGs to enable additional questions to be addressed-eg, the extent to which social and economic progress in a given country is based on unsustainable exploitation of natural systems and whether specific groups are disproportionately negatively affected. Effective governance, tools, and institutional capacity will be required to bring evidence produced through planetary health monitoring into decision making processes. ${ }^{2}$
There are established and emergent examples of the effective use of monitoring that can be built on, including The Demographic and Health Surveys. Environmental monitoring includes remote sensing of land cover, pollution, and other aerosols, and citizen science monitoring of biodiversity and habitats. ${ }^{3}$ Integration of data on the state of natural systems and related human health outcomes, together with effective policy responses at similar spatial and time scales, are envisioned by The Lancet Countdown on health and climate change ${ }^{4}$ and the developing Planetary Health Watch initiative. ${ }^{5}$ Both are examples of monitoring that will be crucial for integrated analyses and for the development of integrated tools to address specific policy needs (panel). Important policy needs include using indicators to track environmental and health trends over time and detecting signals of natural system instabilities that portend health risks. The outputs and outcomes of monitoring and reporting can help ensure the design of effective policy, targets, and actions. For example, the well studied relationship between exposure to $\mathrm{PM}_{2.5}$ and health allows quantification of health effects of exposure to $\mathrm{PM}_{2.5}$ in fire emissions

Panel: Policy applications and examples

Informed assessment

- Assessing both the benefits of action and costs of inaction: strategies for clean energy supply and energy efficiency can lead to improved air quality and reduced air pollution related diseases ${ }^{6}$

- Assessing vulnerability: inform targeted action to address the equity aspects of the environment-health link according to sex, age, location, and income ${ }^{6}$

- Assessing the effectiveness of adaptation and mitigation policies: National Adaptation Plans or Nationally Appropriate Mitigation Actions should have the necessary data to select targets and indicators including those relevant to health

- Quantifying impacts on health and natural systems: inform investment decisions to improve health and reduce environmental risks

Improved understanding

- Raising awareness: increase public pressure for action, inform more responsible behaviour from relevant stakeholders, and enhance the viability of solutions

- Trend analysis including forecasting and backcasting: plan for preparedness and attribution of health effects of environmental change

Taking action

- Designing, targeting, implementing, and evaluating context-appropriate interventions, minimising the potential for adverse unintended consequences

- Supporting existing monitoring efforts, such as for the Sustainable Development Goals to provide data for the annual Voluntary National Reviews for the United Nations High Level Political Forum on Sustainable Development 
For more on the Resolution adopted by the United Nations Eviornment Assembly see http://wedocs.unep.org/ bitstream/handle/ 20.500.11822/28484/English pdf?sequence=3\&isAllowed

For a guide to SDG interactions: from science to implementation see https://council.science/ cms/2017/05/SDGs-Guide-toInteractions.pdf associated with land clearance. In Indonesia, where setting fires to peatlands for agricultural production is common practice, human morbidity and mortality estimates could inform and justify peatland protection activities by helping to prioritise which peatlands to protect, and avoiding fires, could help prevent the greatest human health risks in nearby population centers. ${ }^{7}$ A planetary health understanding could inform interventions that together can protect, or at least minimise harm, to health, peatlands, and biodiversity threatened by fires while reducing greenhouse gas emissions and supporting livelihoods. ${ }^{8}$

The availability and generation of local-level data are persistent challenges, especially data disaggregated by age, sex, social, and other relevant variables that could support more informed analyses on attribution, distributional effects, and useful evidence-based decision-support tools. Moreover, because health and sustainability depend on policies, technologies, and actions across a range of sectors, and because stakeholders therefore tend to be fragmented and siloed, how evidence is presented to different stakeholders matters and must be calibrated carefully to their requirements. Importantly, national stakeholders need to buy into and trust the data. Planetary health researchers and practitioners should work closely with national statistics offices and similar entities while building local research capacities on planetary health, particularly in the global south.

The SDGs, like planetary health, require global leadership and cross-sectoral cooperation for national and local-level actions, and explicit consideration of multiple benefits and trade-offs for health, environment, and sustainable development objectives. An urgent need exists for all key stakeholders to recognise and participate in planetary health. Planetary health is a unifying theme to promote integrated SDG action for governments, the UN system, and other stakeholders, including on the pledge to leave no one behind. Planetary health can move consideration of multiple benefits, trade-offs, and unintended consequences beyond national boundaries, which is also required to achieve the SDGs. For example, efforts in the USA to reduce carbon emissions by supporting biofuel production led to increased demand for palm oil from Indonesia. ${ }^{9}$ As a result, old growth forests and peatlands were cleared for production, releasing stored carbon, ${ }^{10}$ contributing to global greenhouse gas emissions, and adversely affecting human health locally and regionally. A planetary health understanding could have informed early development of mitigation actions and strategies for evaluating policy implementation with a focus on communities most vulnerable and least resilient to the adverse effects on health and wellbeing.

For planetary health to realise its potential in advancing systems thinking and acting for the SDGs, the growing planetary health community should propose an integrated approach to implement planetary health in a coherent manner while continually strengthening and updating the evidence base on the broad landscape of natural systems and human health interactions. Any proposed approach should link strategically to existing policy processes for sustainable development (ie, the SDGs), health (ie, the WHO Global Strategy on Health, Environment and Climate Change and WHO Health Emergency and Disaster Risk Management Framework), environment (the United Nations [UN] Environmental Assembly resolutions on environment health, and pollution issues), climate change (ie, The Paris Agreement), disasters (ie, The Sendai Framework for Disaster Risk Reduction), biodiversity (ie, the post-2020 global biodiversity framework), and others under relevant multilateral environmental agreements.

Coordinated UN agency support to planetary health efforts at the global, national, regional, and local levels will be crucial. The mandates and capacities of the UN system, including the availability, suitability, and feasibility of existing or potential interagency governance structures to support SDG integration and implementation could be explored. Landing planetary health as a unifying theme in countries through domestic SDG planning and financing frameworks, and UN support instruments such as the UN Sustainable Development Framework, is essential.

In the SDG process, countries have flexibility in the strategies they implement to meet their SDG targets. This flexibility provides the opportunity to apply planetary health data and integrated tools to both capitalise on multiple benefits among health and nonhealth sectors, and address trade-offs and unintended consequences of non-health sector policy decisions. For the SDGs and other global processes, the explicit consideration of multiple benefits and trade-offs for health and natural systems of health and non-health 
policies should be the strategic objective for producing and applying integrated tools to support the crosssector engagement and policy coordination needed to protect planetary health. This approach could begin with a focus on a selected set of transformations that address multiple SDGs-eg,the six transformations including smart cities and consumption and production as proposed by The World in 2050 project.

In summary, the association between human health and natural systems can involve complex and dynamic interactions that can lead to health outcomes that are hard to predict and result in unintended consequences. Identifying and implementing interventions to protect planetary health requires a systems-based understanding of their interconnections and feedbacks. Planetary health can be operationalised by the explicit identification of multiple benefits and trade-offs for human health and natural systems of decisions affecting environmental change, consistent with the SDGs. Active outreach on planetary health to the general public and policymakers must be intensified to widen understanding of the importance of issues at the environment and health nexus, including human rights and equity considerations, to co-design a research agenda with decision makers to inform policy development and implementation, and to promote enabling governance conditions for the use of integrated data and tools to protect planetary health.

\section{*Montira J Pongsiri, Sam Bickersteth, Cristina Colón, Ruth DeFries, Mandeep Dhaliwal, Lucien Georgeson, Andrew Haines, Natalia Linou, Virginia Murray, Shahid Naeem, Roy Small, Judit Unguari} The Rockefeller Foundation Economic Council on Planetary Health Secretariat, University of Oxford, Oxford Martin School, Oxford,
OX1 3BD, UK (MJP, SB, LG); United Nations Children's Fund Headquarters, United Nations Plaza, New York, NY, USA (CC); Columbia University, New York, NY, USA (RD, SN); United Nations Development Programme, New York, NY, USA (MD, NL, RS); London School of Hygiene and Tropical Medicine, Centre for Climate Change and Planetary Health, London, UK (AH);

Public Health England, London, UK (VM); and Belmont Forum, Montevideo, Uruguay (JU)

montira.pongsiri@oxfordmartin.ox.ac.uk

We declare no competing interests. The Rockefeller Foundation Economic Council on Planetary Health Secretariat receives funding for planetary health work from The Rockefeller Foundation, although the opinions expressed herein are those of the authors. We thank Cristina Zucca and Pierre Quiblier for their helpful comments, input, and constructive review of the Comment.

Copyright $\odot 2019$ The Author(s). Published by Elsevier Ltd. This is an Open Access article under the CC BY NC-ND 4.0 license.

1 Dhaliwal M, Linou N. Issue brief - planetary health. New York, NY United Nations Development Programme, June 19, 2017.

2 Cash DW, Clark WC, Alcock F, et al. Knowledge systems for sustainable development. Proc Natal Acad Sci USA 2003; 100: 8086-91.

3 Roy HE, Pocock MJO, Preston CD, et al. Understanding citizen science and environmental monitoring. Final report on behalf of UK Environmental Observation Framework. Natural Environmental Research Council Centre for Ecology \& Hydrology and Natural History Museum, November 2012.

4 Watts N, Amann M, Arnell N, et al. The 2018 report of the Lancet Countdown on health and climate change: shaping the health of nations for centuries to come. Lancet 2018; 392: 2479-514

5 Haines A, Hanson C, Ranganathan J. Planetary health watch: integrated monitoring in the Anthropocene epoch. Lancet Planet Health 2018; 2: e141-43.

6 United Nations Environment Programme. Healthy environment, health people Thematic report ministerial policy review session. Second session of the United Nations Environment Assembly of the United Nations Environment Programme, Nairobi, 23-27 May 2016. United Nations Environment Programme, 2016. https://wedocs.unep.org/ bitstream/handle/20.500.11822/17602/K1602727\%20INF\%205\%20Eng pdf? sequence=1\&isAllowed=y (accessed Sept 26, 2019).

7 Marlier M, LiuT, Yu K, et al. Fires, smoke exposure, and public health: an integrative framework to maximize health benefits from peatland restoration. GeoHealth 2019; 3: 178-89.

8 Nawir AA, Murniati, Rumboko L. Forest rehabilitation in Indonesia: where to after more than three decades? Bogor: Center for International Forestry Research, 2007.

9 Searle S. Briefing: international policy and market drivers of Indonesian palm oil demand. The International Council on Clean Transportation, January, 2019. https://theicct.org/sites/default/files/publications/Palm_ Oil_Briefing_20190130_0.pdf (accessed Sept 23, 2019).

10 Danielsen F, Beukema H, Burgess ND, et al. Biofuel plantations on forested lands: double jeopardy for biodiversity and climate. Conserv Biol 2009; 23: $348-58$
For The World in 2050 project website see http://www. twi2050.org 